\title{
The effects of vocabulary knowledge in L2 semantic lexical engagement: The case of adult learners of English as a second language
}

\author{
Verónica García-Castro \\ Department of Education, Faculty of Education, University of Costa Rica, San Pedro-San José, \\ Costa Rica
}

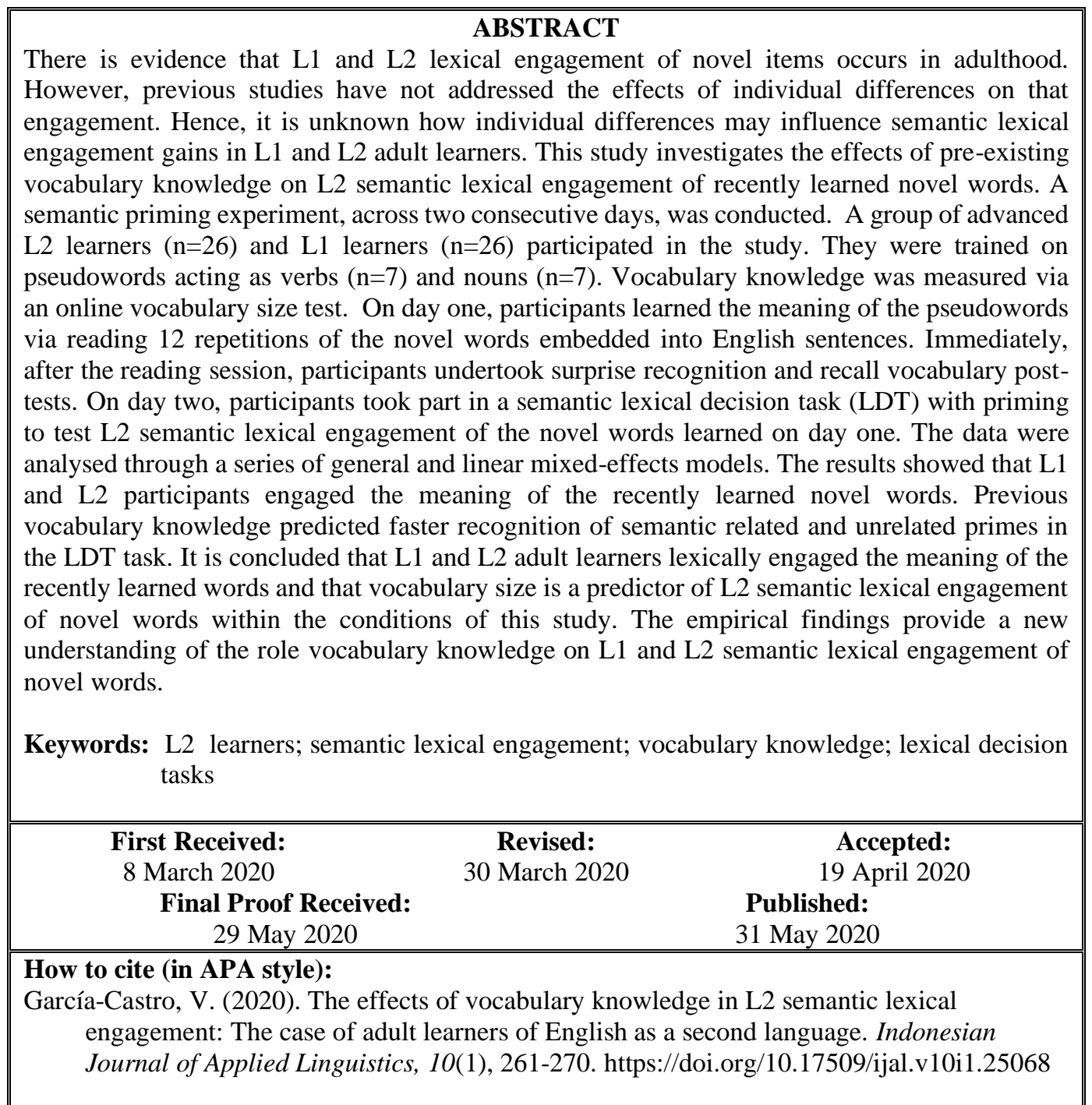

\section{INTRODUCTION}

Word learning in adulthood can be categorised into lexical configuration and lexical engagement (Leach \& Samuel, 2007). The latter refers to the memoristic/static knowledge of the words whereas lexical engagement involves dynamic lexical knowledge (e.g., how a word interacts with other lexical levels and items in the mental lexicon) beyond factual knowledge (Leach \& Samuel, 2007). Research into lexical engagement has been carried out mainly in the first language (L1) (Gaskell \& Dumay, 2003; Leach \& Samuel, 2007; Tamminen \& Gaskell, 2013), and more recently in the second language (L2) (Bordag et al., 2015, 2017, 2018). 
However, the possible effects of individual differences in lexical engagement have not yet been addressed.

Studies on L1 lexical engagement have mainly investigated the engagement of the spoken form of novel words (Gaskell \& Dumay, 2003; Leach and Samuel, 2007). For instance, Gaskell and Dumay (2003) conducted three experiments testing the spoken form of newly learned pseudowords (e.g. lupkin) that have a real baseline word (e.g. napkin) learned via written stimuli. Results of experiment one (i.e. lexical competition in a lexical decision task (LDT)) showed that after twelve repetitions with the target items, emerging spoken forms of the novel words were not robust enough to compete with already established lexical items. However, after 36 encounters with the target items, the emerging lexical representations competed with already known words as seen in delayed-post-tests three days after the exposure tasks (experiment 2) and a week later (experiment 3). Similarly, Leach and Samuel (2007) investigated engagement of spoken form but they employed a combination of written and auditory stimuli. They trained participants on novel words with $/ \delta /$ and $/ \mathrm{s} /$ sounds across five days. Overall, novel words presented lexical engagement gains on day one but with a significant increment in days four and five (over $30 \%$ in comparison to day one). Thus, lexical engagement increased with more repetitions of the target across different days. Tamminen and Gaskell (2013) deviated from lexical engagement of spoken form and tested semantic integration of novel words through visual recognition in two experimental studies with primed, masked and unmasked, lexical decisions. Results from the unmasked LDT showed that novel words act as lexical primes and facilitate semantic recognition of existing familiar words in lexical decisions. The masked LDT revealed that participants responded faster to primed trials than to unprimed trials immediately after training, one day and seven days after training. It is concluded that the novel words integrated into existing semantic networks, given that they showed semantic priming effects in both masked and unmasked primed LDTs. Gaskell and Dumay's (2003), Leach and Samuel's (2007), and Tamminen and Gaskell's (2013) studies proved that adult learners can integrate and engage the meaning and the spoken form of novel words with established lexical items in the mental lexicon. The studies did not aim to research whether individual differences (e.g. vocabulary size) have an effect on lexical engagement of novel words. Thus, it is yet unknown whether they predict lexical engagement gains.

In terms of L2 lexical engagement, recent studies (Bordag et al., 2015, 2017, 2018) have explored semantic lexical engagement of novel words through different learning conditions. For instance, Bordag et al. (2015) investigated incidental learning of novel words (i.e. German-like pseudowords), varying the stimuli complexity, in adult L2 learners of German $(n=76)$. It can be said that this is the first L2 study of its kind that explicitly aimed at testing L2 lexical engagement of recently learned words, in light of Leach and Samuel's (2007) lexical engagement constructs. The study employed a combination of offline (i.e. vocabulary scale and offline statements) and online methods (i.e. selfpaced reading, lexical decision, and semantic priming). Their results showed that L2 learners read syntactically complex texts slower than the simple texts $(M=45.9$ s vs. $M=42.7 \mathrm{~s})$, and that participants were approximately $8 \mathrm{~ms}$ slower when recognising semantically related primes than unrelated primes in the LDT, highlighting lexical engagement gains. A different learning condition was used in Bordag et al. (2017) as they explored semantic lexical engagement via intentional learning in L2 learners of German. However, they also employed German pseudowords as targets. LDT results, of the related condition, showed that items that participants were able to recognise had slower RTs in comparison to those items that participants were able to recognise and recall in an offline vocabulary post-test. Results showed that L2 learners engaged the meaning of novel words with other lexical items but that the strength of that engagement might depend on their ability in recognition and recall processes. Bordag et al. (2018) differed from Bordag et al. $(2015,2017)$ as they tested the strength of semantic lexical engagement of novel words learned deliberately. They conducted two experiments with L2 learners of German. Experiment one targeted novel words whose meanings could be identified with already established semantic representations in the L1. Then, in experiment two, they employed novel words with novel semantic features to be newly established in the semantic network. The overall results showed that newly established L2 words engaged in existing L2 semantic networks, and that their retrieval mechanisms were more effortful than those of novel words with already established semantic representations in the mental lexicon.

In sum, Bordag et al. (2015, 2017, 2018) showed that L2 lexical engagement of meaning occurs in L2 word learning. However, they have only tested L2 learners of German, and there is a lack of consistency in learning conditions. To illustrate, Bordag et al. (2015) investigated L2 lexical engagement through incidental learning, Bordag et al. (2017) via intentional learning, and Bordag et al. (2018) through deliberate learning. Thus, it is not yet known if lexical engagement of meaning occurs via intentional learning in populations who are not L2 learners of German as, to the researcher's knowledge, there has been only one study corroborating L2 lexical engagement via intentional learning (Bordag et al., 2017). In addition, the studies' scope did not consider learners' individual differences in lexical 
engagement of novel words; hence, more research in this area is needed.

This study aims to fill the theoretical gap previously mentioned by exploring whether learners' individual differences in vocabulary knowledge have an effect on L2 semantic lexical engagement of novel words learned intentionally via sentence reading. It is known that adults consolidate new information faster due to their pre-existing knowledge (Wilhelm et al., 2008; Wilhelm et al., 2013), and that pre-existing vocabulary knowledge speeds up learning of new words due to the context where they are embedded (Perfetti et al., 2005). In addition, vocabulary knowledge is a predictor of L1 online word recognition (Yap et al., 2012; Mainz et al., 2017) and L2 word learning (García-Castro, 2015) with both vocabulary recognition and recall being predictors of L2 reading ability (Laufer \& Aviad-Levitzky, 2017). Vocabulary knowledge is then a predictor of word learning and processing; thus, it may predict semantic lexical engagement of novel words.

This is the first empirical study to investigate the possible effects of pre-existing vocabulary knowledge in semantic lexical engagement as previous studies have not done so (Bordag et al., 2015， 2017, 2018; Leach \& Samuel, 2007; Tamminen \& Gaskell, 2013).

This study aims to answer two main research questions as follow.

1. Are L2 adult learners of English able to semantically engage novel words?

2. Does vocabulary knowledge have effect on L2 semantic lexical engagement of novel words?

\section{METHOD}

A semantic priming experiment modelled on Batterink and Neville (2011) was employed to determine whether participants' semantic knowledge of recently learned novel words engaged with other words in the mental lexicon and if vocabulary knowledge had an effect on that engagement. The experiment aimed to explore, at a semantic level, if the recently learned pseudowords acting as primes would activate lexical related items (Rodd et al., 2013). Lexical engagement was measured via a semantic LDT with priming given that if novel items have been integrated in established lexical-semantic networks, they would act as effective primes (Tamminen \& Gaskell, 2013). One of the advantages of using semantic priming is that it facilitates processing of semantically related words (McDonough \& Trofimovich, 2009), and it is one of the most established examples of lexical engagement (Leach \& Samuel, 2007). LDTs have been successfully used in previous lexical engagement studies (Bordag et al., 2015, 2017, 2018; Tamminen \& Gaskell, 2013). Thus, they can be considered suitable for this study. Offline meaning recognition and recall of the novel words prior to their lexical engagement were also taken into account.

It was predicted that participants would recognise and recall the meaning of the target items in the offline vocabulary post-tests (García-Castro, 2015; Pellicer-Sánchez, 2010, 2015; Webb, 2007, 2008), that they would engage the meaning of the target pseudowords with other lexical items (Bordag et al., 2015; 2017, 2018; Leach \& Samuel, 2007; Tamminen \& Gaskell, 2013), and that their vocabulary size would predict lexical engagement gains given that vocabulary knowledge is associated with faster and more accurate word recognition (Yap et al., 2012).

\section{Participants}

Twenty-six advanced L2 adult Spanish native speakers (female $=14$, male $=12, \mathrm{M}$ age 30.31 years, $\mathrm{SD}=6.47, \min =19, \max =42$ ) took part in this study. All participants had taken the IELTS tests and scored at least seven on all abilities $(\mathrm{M}=7.73 ; \mathrm{SD}=0.47$, $\min =7, \max =8.5)$. Twenty-six adult native speakers, (female $=18$, male $=8, \mathrm{M}$ age 22.22 years, $\mathrm{SD}=5.62$, $\min =18, \max =45$ ) also participated in the study to have a L1 base line for comparison (PellicerSánchez, 2015). All participants were studying at a university in the United Kingdom and they all had normal or corrected-to-normal vision.

\section{Stimuli}

The stimuli for this study comprised English-like pseudo-verbs $(n=7)$, pseudo-nouns $(n=7)$, and fillers $(n=7)$ embedded into English sentences. All the pseudowords were four letters long and they were created with the ARC Nonword Database (Rastle et al., 2002). They were piloted with English native speakers $(n=10)$ for phonological norming. Novel semantic meanings modelled on Tamminen and Gaskell (2013) were created for each pseudoword (i.e. Fowd: "type of sweet and dry wine"). Then, fifteen sentences per pseudoword were designed to embed the novel words. Every sentence comprised twenty words, all part of the 3000 most frequent words in the English language (Pellicer-Sánchez, 2010; 2015). They only included one target pseudoword to achieve text coverage of $95 \%$ (Hu \& Nation, 2000). The sentences were normed to ensure the context supported possible emerging semantic representations of the novel words (Elgort et al., 2016). Thirty advanced L2 learners and 30 English monolinguals were selected for the piloting phase. They read five different sentences per target pseudoword and were asked to guess the meaning of the pseudowords in each sentence. Responses were rated by a Spanish native speaker with an advanced L2 English proficiency level and by an English monolingual who did not take part in the study. Modifications were made to ensure accurate English sentences for the pseudowords' learning context. Twelve sentences per pseudoword were selected as 
the learning stimuli to guarantee 12 encounters with the target items since more than 10 repetitions with the novel words are needed to strengthen vocabularylearning gains (Webb, 2008).

\section{Instruments}

Surprise recognition and recall offline vocabulary post-tests (Webb, 2008) were used to assess participants' semantic knowledge of the novel words $(n=14)$ and fillers $(n=7)$ prior to their lexical engagement. In the semantic recognition test participants had to recognise the meaning of the novel words via a multiple-choice exercise. For semantic recall, L2 learners were asked to translate the novel words into their L1 and L1 learners had to provide a synonym of each target item.

Lexical engagement was tested through a semantic lexical decision task with priming. Each target item, and filler, belonged to the 3000 most frequent words of the British National Corpus (BNC) to ensure participants' understanding. Experimental and filler items were matched with a semantically related English word ( $\mathrm{M}$ length=4.26; $\mathrm{SD}=0.60$ ), a semantically unrelated English word (M length=3.90; $\mathrm{SD}=0.89$ ), and two English-like nonwords (M length 4.01; $\mathrm{SD}=0.28)$. The targets did not appear in the training session to avoid the formation of associative semantic links between them and the novel words during training (Tamminen \& Gaskell, 2013).

An online vocabulary size test (Meara \& Milpareux, 2016) measured participants' vocabulary knowledge. The scores given at the end of each test were registered to account for vocabulary size.

\section{Procedures}

The experiment was conducted in two consecutive days. On day one, participants were seen individually in a laboratory environment where they took the vocabulary size test and then they continued with the experiment's learning phase. Participants were instructed to read the sentences, which served as stimuli, on a computer screen that lasted for five seconds. Each screen was followed by a fixation cross-displayed for $1500 \mathrm{~ms}$ and participants had to press the spacebar on the keyboard to see the next screen with a new sentence. They answered comprehension questions every eighth trial in order to maintain their attention. Soon after they finished reading the sentences, they were asked to read a short definition, modelled on Tamminen and Gaskell's (2013) work, of each pseudoword on a computer screen. Participants read the decontextualised definitions of each target word only once (Bordag et al., 2017) and without time constraints. They had to press the spacebar to change screen and to see the next definition. Immediately after the learning phase, surprise recognition and recall vocabulary post-tests were conducted to test participants' factual knowledge of the semantic characteristics of the novel words.
After a sleep consolidation period of 24 hours, participants were again seen individually (day 2) in a laboratory environment. They were asked to sit in front of a computer screen and to read the experiment's welcoming screen and instructions. Once they finished reading the instructions, they had to press the spacebar key on the keyboard to proceed to the practice trials. They were instructed to read a prime (i.e. recently learned novel word) and a target word and pressed a key on the keyboard labelled "word" if the target was an English word and a keylabelled "Nonword" if the target was not an English word. Every trial started with a fixation cross, shown at the centre of the screen (i.e. $1200 \mathrm{~ms}$ ), then the prime (i.e. $200 \mathrm{~ms}$ ), and the target word (i.e. $300 \mathrm{~ms}$ ). The following trial started $300 \mathrm{~ms}$ after the participant's answer (Batterink \& Neville, 2011). Participants undertook 16 practice trials before the 56 experimental trials and 28 filler trials.

\section{FINDINGS \\ Offline Tests \\ Participants' Vocabulary Post-tests}

Participants' vocabulary post-tests were examined to determine whether they had configurational knowledge of the novel words prior to their lexical engagement. Table 1 presents the descriptive statistics of participants' vocabulary post-tests. Overall, L1 learners scored higher in the recognition $(\mathrm{M}=0.91 ; \mathrm{SD}=0.29)$ and recall $(\mathrm{M}=0.67 ; \mathrm{SD}=0.47)$ vocabulary post-tests than L2 learners $(\mathrm{M}=0.85$; $\mathrm{SD}=0.35$ and $\mathrm{M}=0.59 ; \mathrm{SD}=0.49$ respectively).

\section{Table 1}

Mean \% Accuracy Scores (SD) on the Vocabulary Post-tests

\begin{tabular}{lcl}
\hline & Recognition & Recall \\
\hline L2 learners & $85(35)$ & $59(49)$ \\
L1 learners & $91(29)$ & $67(47)$ \\
\hline
\end{tabular}

Table 1 shows that all participants recognised and recalled the novel words prior to their lexical engagement. This indicates that they had factual knowledge of the recently learned pseudowords in line with studies using offline measures of word recognition and recall (García-Castro, 2015; PellicerSánchez, 2010; Webb, 2007, 2008; Webb \& Chang, 2015). L1 and L2 differences in offline vocabulary post-tests have been previously found (GarcíaCastro, 2015; Pellicer-Sánchez, 2015), and they are likely to occur given L1 and L2 processing differences (Dronjic \& Bitan, 2016; Segalowitz, 2010; Tokowics, 2015).

As expected, recognition scores are larger than those of recall because participants are likely to show more receptive than productive knowledge (Schmitt, 2010). These differences were confirmed in logistic regression analyses on the (binary) accuracy scores using the package "glm" (Davies, 1992) in the R 
studio environment (R Studio Development Core Team, 2015). One model had receptive scores as a fixed factor, the second model had recall scores as fixed factors, L1 Group (Spanish/English) and vocabulary size as predictors, and subjects and items as random intercepts. An effect of L1 was found on the recall $(\beta=-0.37082, Z$ value $=-2.714, p<0.01)$ and recognition scores $(\beta=-0.4942, Z$ value $=-2.402$, $\mathrm{p}<0.05)$ given the L1 and L2 differences previously mentioned.

A main effect of vocabulary size was found in the recognition $(\beta=2.819 \mathrm{e}-04, \mathrm{Z}$ value $=2.587, \mathrm{p}<$ $0.01)$ and recall scores $(\beta=5.246 \mathrm{e}-04, \mathrm{Z}$ value $=$ $5.550, \mathrm{p}<0.001)$ irrespective of language group, showing that participants with greater vocabulary sizes outperformed those with smaller vocabularies. To illustrate, L1 learners with greater vocabularies scored higher in the recognition $(\mathrm{M}=0.97$ vs. $\mathrm{M}=0.73)$ and recall $(\mathrm{M}=0.76$ vs. $\mathrm{M}=0.43)$ vocabulary post-tests. L2 learners with greater vocabularies also showed higher recognition $(\mathrm{M}=0.97$ vs. $\mathrm{M}=0.81)$ and recall scores $(M=0.70$ vs. $M=0.55)$ of the novel words than those with smaller vocabularies. Vocabulary size then seems to be a predictor of offline recognition and recall scores of newly learned words (García-Castro, 2015).

\section{Research Question 1}

In order to determine whether participants engaged the meaning of the novel words, the accuracy scores and reaction times in the LDT responses were analysed.

\section{LDT Responses}

Accuracy

Descriptive statistics for the accuracy scores are displayed in Table 2. L1 and L2 learners accurately recognised most of the words and nonwords in every condition. These results were tested in a logistic regression analysis on the (binary) accuracy scores using the package "glm" (Davies, 1992) in the R studio environment ( $\mathrm{R}$ Studio Development Core Team, 2015). The model had accuracy scores as a fixed factor, relatedness (semantically related/semantically unrelated/nonword), L1 Group (Spanish/English) and vocabulary size as predictors, and subjects and items as random intercepts.

Table 2

\begin{tabular}{|c|c|c|c|}
\hline & Related & Unrelated & Nonwords \\
\hline L2 Learners & $95(22)$ & $92(27)$ & $79(41)$ \\
\hline L1 Learners & $85(36)$ & $87(34)$ & $97(15)$ \\
\hline
\end{tabular}

An interaction between relatedness-nonword and L1 $(\beta=-2.8206, \mathrm{SE}=0.8099, \mathrm{z}=-4.174, \mathrm{p}<0.001)$ was found as L2 learners made significantly less accurate responses in the nonword condition than L1 learners $\quad(\mathrm{M}=0.77$ vs. $\mathrm{M}=0.97$ respectively). Interactions between nonwords and vocabulary size $(\beta=0.0002207, \quad S E=3.659 e-04, \quad t=3.222, \quad p<0.001)$ were also found because participants with greater vocabulary knowledge made more accurate responses, in the nonword condition, than those with smaller vocabularies $(\mathrm{M}=0.91$ vs. $\mathrm{M}=0.83)$. These results highlight that participants' pre-existing vocabulary knowledge aided their recognition of nonwords in the LDT task.

\section{Reaction times}

Reaction times that were correctly recognised in the offline recognition vocabulary post-test, and that were accurately identified in the LTD, were analysed (Bordag et al., 2017). Then, individual responses below $150 \mathrm{~ms}$ and above $1500 \mathrm{~ms}$ were removed (Tamminen \& Gaskell, 2013), affecting $13.6 \%$ of the Spanish data and $4 \%$ of the English data. Descriptive statistics of participants' RTs are displayed in Table 3 .

L1 learners reacted faster than L2 learners in every condition condition. To illustrate, L1 learners reacted $17 \mathrm{~ms}$ faster in the semantically related condition when compared to the unrelated condition, and L2 learners were $8 \mathrm{~ms}$ faster in the semantically related condition than in the unrelated. This result, while preliminary, suggests that L1 and L2 learners may have been semantically primed as lexical decisions are known to be faster when primed with a semantically related word (Bordag et al., 2015, 2017, 2018; Francis, 2005; Tamminen \& Gaskell, 2013).

Table 3

Mean \% Accuracy Scores (SD) on the LDT Reaction Times

\begin{tabular}{lccr}
\hline & Related & Unrelated & Nonwords \\
\hline L2 Learners & $681(236)$ & $689(247)$ & $805(265)$ \\
L1 Learners & $595(226)$ & $612(206)$ & $683(235)$ \\
\hline
\end{tabular}

Table 3 shows that, overall, L1 and L2 learners reacted faster to semantically related items than to unrelated items and nonwords. This was confirmed in a linear mixed-effect model using the package "Imertest" (Kuznetsova et al., 2017) in the R studio environment ( $\mathrm{R}$ Studio Development Core Team, 2015). RTs were entered as a fixed factor, relatedness (semantically related/semantically unrelated), L1 Group (Spanish/English) and recall score (from the offline configuration task) as predictors. Subjects and items (primes) were entered as random factors, with L1 group, and relatedness as random intercepts. A significant main effect of L1 was found $(\beta=121.56$, $\mathrm{SE}=47.25, \mathrm{t}=2.573, \mathrm{p}<0.05)$, and an interaction between L1 and relatedness $(\beta=71.07 \mathrm{SE}=32.43$, $\mathrm{t}=2.191, \mathrm{p}<0.05)$ confirming L1 and L2 faster RTs in the semantically related condition, and L2 slower RTs irrespective of relatedness and condition (Table 3). These results highlight that L1 and L2 participants were semantically primed with the recently learned novel words hence they acted as effective primes (Tamminen \& Gaskell, 2013). The 
results suggest that $\mathrm{L} 1$ and $\mathrm{L} 2$ learners engaged the meaning of the recently learned novel words.

\section{Research Question 2}

\section{Participants' Vocabulary Size}

Descriptive statistics of participants' vocabulary size are shown in Table 4. L1 learners outperformed L2 learners in their vocabulary size. However, given that L1 speakers may have had more exposure to the English language than L2 learners (Kaan, 2014), no comparisons between the two language groups were made.

Table 4

Mean Scores (SD) of Participants' Vocabulary Size Scores

\begin{tabular}{lc}
\hline & Vocabulary Size \\
\cline { 2 - 2 } L2 Learners & $7557(775)$ \\
L1 Learners & $8710(1057)$ \\
\hline
\end{tabular}

In order to assess if participants' pre-existing vocabulary knowledge has effect on semantic lexical engagement, a linear mixed-effect model using the package "Imertest" (Kuznetsova et al., 2017) in the R studio environment (R Studio Development Core Team, 2015) was used. RTs were entered as a fixed factor, relatedness (semantically related/semantically unrelated), L1 Group (Spanish/English), recall score (from the offline configuration task), and vocabulary knowledge as predictors. Subjects and items (primes) were entered as random factors, with L1 group, and relatedness as random intercepts.

There was a main effect of vocabulary size $(\beta=-$ $0.4418, \mathrm{SE}=0.02129, \mathrm{t}=-2.075, \mathrm{p}<0.05)$ as RTs were sped up by larger vocabulary sizes irrespective of language group and relatedness. In order to further illustrate the result, a median split of participants' vocabulary size (L1 Mdn=9370; L2 Mdn=7691) was performed. Participants were then divided into high and low vocabulary size groups based on the median split.

Table 5 illustrates the descriptive statistics of the vocabulary size groups.

Table 5

Mean Scores (SD) of Participants' Vocabulary Size Groups

\begin{tabular}{lcc}
\hline & High Vocabulary & Low Vocabulary \\
\cline { 2 - 3 } L1 Learners & $9545(173)$ & $8031(986)$ \\
L2 Learners & $8247(436)$ & $6977(457)$ \\
\hline
\end{tabular}

It was found that higher vocabulary groups outperformed lower groups irrespective of L1 and relatedness supporting previous L1 studies (Mainz et al., 2017; Yap et al., 2012). For instance, the L1 higher vocabulary group reacted approximately $195 \mathrm{~ms}$ faster than the lower group $(M=620$ vs. $\mathrm{M}=815$ respectively), and the L2 higher group reacted $301 \mathrm{~ms}$ faster than the lower group ( $\mathrm{M}=725$ vs. $M=1026$ ) (Figure 1).
Figure 1

Overall Reaction Times in each Vocabulary Size Group

Overall RTs per Vocabulary Size Group

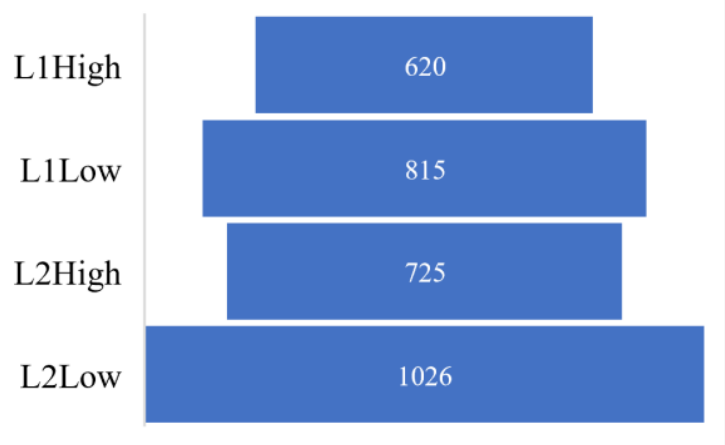

In terms of relatedness, in the semantically related condition the L1 higher vocabulary group outperformed the lower group by approximately $88 \mathrm{~ms}(\mathrm{M}=605$ vs. $\mathrm{M}=693)$. In the case of the $\mathrm{L} 2$ learners, the higher group was $138 \mathrm{~ms}$ faster than the lower group ( $M=640$ vs. $M=778$ ) (Figure 2).

As can be seen in Figure 2, larger vocabulary sizes sped up L1 and L2 RTs in every condition in accordance with previous L1 studies (Yap et al., 2012; Mainz et al., 2017). These results also suggest that L2 larger vocabularies contributed to faster semantic recognition of recently learned novel words. In general, therefore, the empirical data highlights that vocabulary knowledge is a predictor of L1 and L2 semantic lexical engagement.

\section{DISCUSSION}

This study set out to investigate the effects of prior vocabulary knowledge in L2 semantic lexical engagement. The results suggest that L2 learners semantically engaged the novel words and that vocabulary knowledge has a significant effect in that engagement.

\section{Are L2 adult learners of English able to engage novel words semantically?}

The results revealed that L2 adult learners of English are able to semantically engage novel words as they were semantically primed with the recently learned novel words. Participants developed a meaningful lexical entry of the recently learned novel words since they can quickly and accurately access lexical information that is semantically related or unrelated to them (Batterink \& Neville, 2011; Bordag et al., 2017; Rod et al., 2012; Tamminen \& Gaskell, 2013). This demonstrates that the emerging lexical representations, of the novel words, were robust enough to act as effective primes confirming that they have been integrated into established lexicalsemantic networks (Tamminen \& Gaskell, 2013). This finding is consistent with previous studies indicating that L1 (Gaskell \& Dumay, 2003; Leach \& 
Samuel, 2007; Tamminen \& Gaskell, 2013) and L2 learners lexically engage the meaning of novel words (Bordag et al., 2015, 2017, 2018). However, it also confirms that this occurs in L2 learners of English.

Another relevant finding is that L1 learners were faster than L2 learners when recognising the novel words. L2 learners' slower RTs may be related to L1 and L2 language processing differences. For instance, for L1 speakers lower-level processes (e.g. recognition (Dronjic \& Bitan, 2016)) are in most cases automatic $^{\mathrm{i}}$ whereas for L2 language users some of those processes may not be automatised yet in their second language. Hence, L2 learners may exhibit higher processing costs during language processing made apparent by slower reading times and slower RTs. In addition, given that L2 comprehension might be less accurate, more effortful, and more time and resource consuming (Dijkgraaf et al., 2017) than L1 comprehension, this may have generated longer L2 RTs in the lexical decision task. It is also worth noting that L2 learners carry out parallel lexical processes and operations of two different languages simultaneously (de Groot, 2011; Dijkstra \& Van Heuven, 2002) and this makes their word learning and processing differ from that of L1 speakers. For instance, concepts that are linked to L1 and L2 words may present bidirectional transfer while reading (Wolter \& Helms-Park, 2016) and this might have affected the L2 learners in this study. L1 and L2 languages processing varies significantly and this may explain the differences in RT between the L1 and L2 learners found in this study.

Figure 2

RTs in High and Low Vocabulary Groups

RTs in High and Low Vocabulary Size Groups

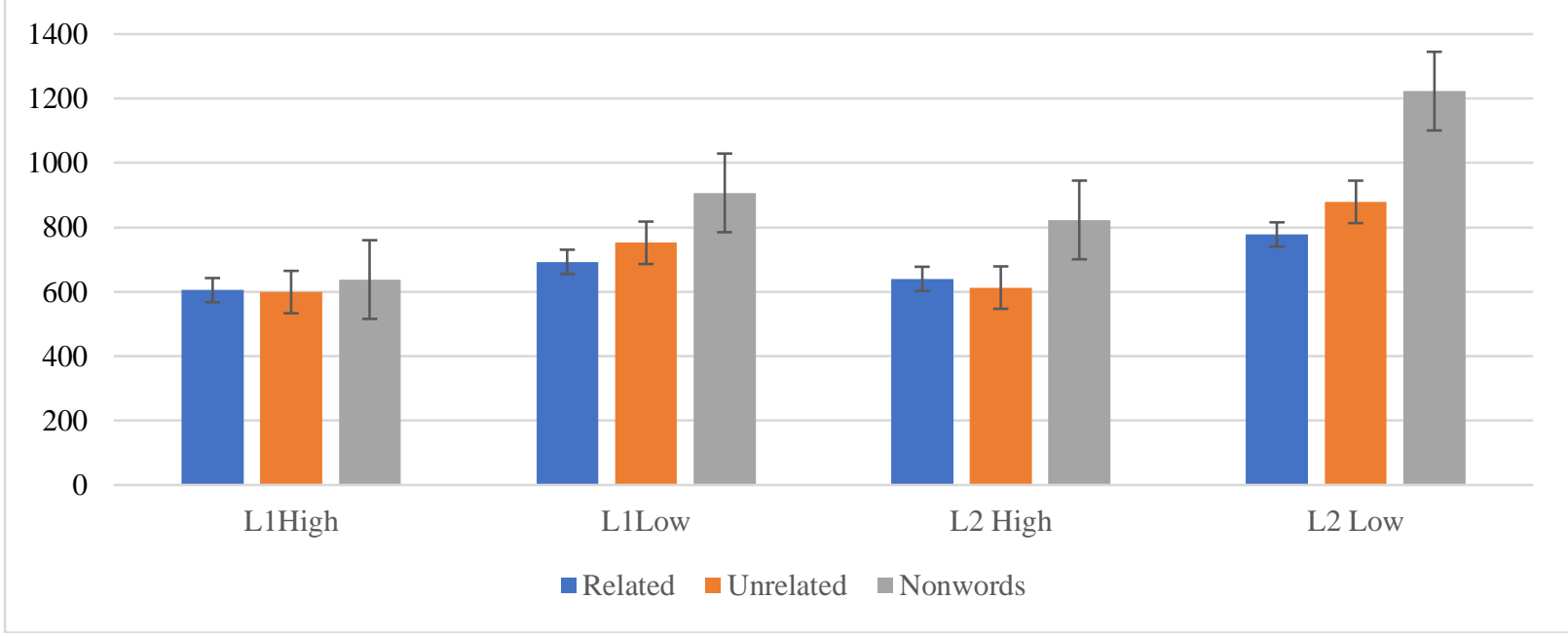

Does vocabulary knowledge have effect on $\mathrm{L} 2$ semantic lexical engagement of novel words?

The empirical findings of this study suggest that preexisting vocabulary knowledge has an effect on L2 semantic lexical engagement of novel words as it sped up L1 and L2 recognition of semantically related and unrelated words in the LDT. Word recognition occurs when the word's representation, in the mental lexicon, has been accessed (Harley, 2014). Thus, one can assume that participants had developed a lexical representation of the novel words in their mental lexicon, as they were able to access and recognise them, and greater vocabularies seem to have aided that recognition. It is likely that having greater vocabulary knowledge contributes to faster semantic lexical activation in the mental lexicon and thus participants are able to react quicker to semantic related and unrelated primes. This finding further supports previous studies in that L1 larger vocabulary speeds up online word recognition (Mainz et al., 2017; Yap et al., 2012), and it also confirms that this occurs in the L2. To the researcher's knowledge, this is the first study to demonstrate that vocabulary knowledge is a predictor of L2 semantic lexical engagement. These novel findings provide a new understanding of the effects pre-existing vocabulary knowledge may have on semantic lexical engagement.

Greater vocabulary knowledge may have also contributed to the participants' ability to understand, process, and derive meaning from context (Elgort et al., 2016; Eynsenck \& Kane, 2015; Perfetti et al., 2005) facilitating novel word learning beyond factual knowledge. The highly controlled written context in the study, where the pseudowords were embedded, may have facilitated participants' understanding and semantic lexical engagement because in reading processes readers use the context to infer meaning (Bordag et al., 2015; Eynsenck \& Kane, 2015). In addition, the number and quality of encounters with the novel words may have also aided their learning (Perfetti, 2007; Perfetti \& Hart, 2002; Webb, 2007) because every encounter with a target word leaves a memory trace (e.g. code) in the mental lexicon that is 
reinforced every time the learner encounters it. In this study, the number of repetitions and quality of the learning context (i.e. extensively piloted, sentence length and vocabulary frequency in the sentences were controlled for) could have activated memory traces of the novel words and words already established in participants' mental lexicon (Bordag et al., 2017). Therefore, participants with greater vocabularies may have had more lexical resources to activate lexical items via spreading activation that helped them recognise and understand the written context.

It is worth noting that the participants in this study only had 12 exposures to the target items and Leach and Samuel (2007) found lexical engagement gains after 24 encounters. However, providing the meaning of the target words after the reading task seems to have strengthened their semantic lexical engagement. This finding has important implications for the fields of L2 vocabulary teaching and learning, and for material developers. For instance, L2 teachers may implement teaching techniques to provide students with a definition of novel words after reading tasks to help them achieve semantic knowledge beyond factual memorisation. The findings also suggest that knowing more L2 words may lead to L2 semantic lexical engagement of novel words; thus, this information can be used to promote the relevance of reading to achieve vocabulary knowledge beyond factual memory. The findings on vocabulary knowledge also highlighted that L1 and L2 participants with greater vocabularies showed more offline recognition and recall of novel words probably because of the learning circumstances mentioned above and the L1 and L2 lexical processing differences already explained.

The findings of this study on vocabulary knowledge highlight the benefits larger vocabularies may have when learning L2 novel words beyond memorisation. This new information can be used to develop $\mathrm{L} 1$ and $\mathrm{L} 2$ reading and teaching practices to promote vocabulary learning in adulthood. It is recommended that learners engage in more reading practices inside and outside classroom contexts to achieve semantic lexical engagement of novel words.

\section{CONCLUSION}

This study was conducted to investigate the effect vocabulary knowledge may have on L2 semantic lexical engagement of novel words. The empirical findings suggest that vocabulary knowledge predicts L2 semantic lexical engagement of novel words under the conditions of this study. These findings provide a new understanding of the role vocabulary knowledge has on L1 and L2 word learning and lexical engagement of novel words, given that, to the best of the researcher's knowledge, this is the only empirical investigation into the effects of vocabulary knowledge in L2 semantic lexical engagement of novel words.

This study has some limitations. Firstly, participants' reading behaviour may have been caused to change when pseudowords were used as targets instead of existing words. Secondly, the pseudowords in this study had regular English spellings and this does not simulate the learningburden of real English words (Elgort et al., 2016). Thirdly, there is an uneven number of targets responded to amongst the participants and this makes it more difficult to generalise the results. In addition, this study only explored the effects of vocabulary knowledge on L2 semantic lexical engagement and it did not consider other individual differences such as phonological working memory, verbal fluency, and reading skills. Future studies should include such individual differences to fully explore the extent of L2 semantic lexical engagement. It is also suggested that other populations are taken into account and not only adult learners of English as an L2. For instance, future research could explore L2 semantic lexical engagement in childhood and in EFL classroom contexts. In conclusion, the empirical findings of this study provide a new and more comprehensive understanding of the role vocabulary knowledge has on L2 vocabulary learning beyond factual knowledge.

\section{ACKNOWLEDGEMENTS}

I would like to thank the University of Costa Rica for its support to conduct this study. I would also like to thank my Ph.D supervisors who contributed to the theoretical and methodological insights of this study during my Ph.D studies. Finally, thanks to the participants for their time and interest in the study.

\section{REFERENCES}

Batterink, L., \& Neville, H. (2011). Implicit and explicit mechanisms of word learning in a narrative context: an event-related potential study. Journal Cognitive Neuroscience, 23(11), 3181-3196. https://doi.org/10.1162/jocn_a_00013

Bordag, D., Opitz, A., Rogahn, M., \& Tschirner, E. (2018) Representations of new words with different properties in the L2 semantic network. The Mental Lexicon, 13(1), 74-104. https://doi.org/10.1075/ml.17005.bor

Bordag, D., Kirschenbaum, A., Rogahn, M., Opitz, A., \& Tschirner, E. (2017). Semantic representation of newly learned L2 words and their integration in the L2 lexicon. Studies in Second Language Acquisition, 39(01), 197212. https://doi.org/10.1017/s0272263116000048

Bordag, D., Kirschenbaum, A., Tschirner, E., \& Opitz, A. (2015). Incidental acquisition of new 
words during reading in L2: Inference of meaning and its integration in the L2 mental lexicon. Bilingualism: Language and Cognition, 18(03), 372-390. https://doi.org/10.1017/s1366728914000078

de Groot, A. (2011). Language and cognition in bilinguals and multilinguals: An introduction. Psychology Press.

Dijkstra, T., \& van Heuven, W. J. B. (2002). The architecture of the bilingual word recognition system: From identification to decision. Bilingualism: Language and Cognition, 5(03), 175-197. https://doi.org/10.1017/s1366728902003012

Dijkgraaf, A., Hartsuiker, R. J., \& Duyck, W. (2017). Predicting upcoming information in native-language and non-native-language auditory word recognition. Bilingualism: Language and Cognition, 20(5), 917-930. https://doi.org./10.1017/S1366728916000547

Dronjic, V., \& Bitan, T. (2016). Reading, brain, and cognition. In X. Chen, V. Dronjic, \& R. Helms-Park (Eds.), Reading in a second language: Cognitive and psycholinguistic issues. Routledge.

Elgort, I., Candry, S., Boutorwick, T., Eyckmans, J., \& Brysbaert, M. (2016). Contextual Word Learning with Form-Focused and MeaningFocused Elaboration. Applied Linguistics, 39(5), 646-667. https://doi.org/10.1093/applin/amw029

Eysenck, M., \& Kane, M. (2015). Cognitive psychology: A student's handbook (7th ed.). Psychology Press.

Francis, N. (2005). Research findings on early first language attrition: Implications for the discussion on critical periods in language acquisition. Language Learning, 55(3), 491531. https://doi.org/10.1111/j.00238333.2005.00313.X

García-Castro, V. (2015). Individual differences and intake of novel words in L2 written input. York Papers in Linguistics, 3, 18-30. https://www.researchgate.net/publication/3060 78181_INDIVIDUAL_DIFFERENCES_AND _INTAKE_OF_NOVEL_WORDS_IN_L2_W RITTEN_INPUT

Gaskell, M. G., \& Dumay, N. (2003). Lexical competition and the acquisition of novel words. Cognition, 89(2), 105-132. https://doi.org/10.1016/s0010-0277(03)000702

Harley, T. A. (2014). The psychology of language from data to theory. Psychology Press.

$\mathrm{Hu}$, M., \& Nation, P. (2000). Unknown vocabulary density and reading comprehension. Reading in a Foreign Language, 13(1), 403-430. https://eric.ed.gov/?id=EJ626518

Kaan, E. (2014). Predictive sentence processing in L2 and L1: What is different? Linguistic
Approaches to Bilingualism, 4(2), 257-282. https://doi.org/10.1075/lab.4.2.05kaa

Kuznetsova, A., Brockhoff, P. B., \& Christensen, R. H. B. (2017). lmerTest package: Tests in linear mixed effects models. Journal of Statistical Software, 82(13), 1-26. https://doi.org/10.18637/jss.v082.i13

Laufer, B., \& Aviad-Levitzky, T. (2017). What type of vocabulary knowledge predicts reading comprehension: Word meaning recall or word meaning recognition? The Modern Language Journal, 101, 729-741. https://doi.org/10.1111/modl.12431

Leach, L., \& Samuel, A. G. (2007). Lexical configuration and lexical engagement: When adults learn new words. Cognitive Psychology, 55(4), 306-353. https://doi.org/10.1016/j.cogpsych.2007.01.001

Mainz, N., Shao, Z., Brysbaert, M., \& Meyer, A. S. (2017). Vocabulary knowledge predicts lexical processing: Evidence from a group of participants with diverse educational backgrounds. Frontiers in Psychology, 8, 1164. https://doi.org/10.3389/fpsyg.2017.01164

McDonough, K., \& Trofimovich, P. (2009). Using Priming Methods in Second Language Research. Routledge.

Meara, P., \& Milpareux., I. (2016). Tools for researching vocabulary. Multilingual Matters.

Pellicer-Sánchez, A. (2010). Incidental vocabulary acquisition from an authentic novel: Do Things Fall Apart?. Reading in a Foreign Language (Online), 22(1), 31-55. http://nflrc.hawaii.edu/rfl/April2010/articles/pe llicersanchez.pdf

Pellicer-Sánchez, A. (2015). Incidental L2 Vocabulary Acquisition from and While Reading. Studies in Second Language Acquisition, 38(01), 97-130. https://doi.org/10.1017/s0272263115000224

Perfetti, C. (2007). Reading ability: Lexical quality to comprehension. Scientific Studies of Reading, 11(4), 357-383. https://doi.org/10.1080/10888430701530730

Perfetti, C. A., \& Hart, L. (2002). The lexical quality hypothesis. In L. Vehoeven, C. Elbro, \& P. Reitsma (Eds.), Precursors of Functional Literacy (pp. 189-213). John Benjamins.

Perfetti, C. A., Wlotko, E. W., \& Hart, L. A. (2005). Word learning and individual differences in word learning reflected in event-related potentials. Journal of Experimental Psychology: Learning, Memory, and Cognition, 31(6), 1281-1292. https://doi.org/10.1037/0278-7393.31.6.1281

R Core Team (2015). R: A language and environment for statistical computing. (Version 4.0.0). R Foundation for Statistical Computing. https://www.R-project.org/ 
Rastle, K., Harrington, J., \& Coltheart, M. (2002). 358,534 nonwords: the ARC Nonword Database. The Quarterly Journal of Experimental Psychology A, 55(4), 1339-1362. https://doi.org/10.1080/02724980244000099

Rodd, J. M., Cutrin, B. L., Kirsch, H., Millar, A., \& Davis, M. H. (2013). Long-term priming of the meanings of ambiguous words. Journal of Memory and Language, 68(2), 180-198. https://doi.org/10.1016/j.jml.2012.08.002

Schmitt, N. (2010). Researching vocabulary: A vocabulary research manual. Palgrave Press

Segalowitz, N. (2010). The cognitive bases of second language fluency. Routledge.

Tamminen, J., \& Gaskell, M. G. (2013). Novel word integration in the mental lexicon: Evidence from unmasked and masked semantic priming. Quarterly journal of experimental psychology, 66(5), 1001-1025. https://doi.org/10.1080\%2F17470218.2012.72 4694

Tokowicz, N. (2014). Lexical processing and second language acquisition. Taylor \& Francis Ltd.

Webb, S. (2007). The effects of repetition on vocabulary knowledge. Applied Linguistics, 28(1), 46-65. https://doi.org/10.1093/applin/aml048

Webb, S. (2008). The effects of context on incidental vocabulary learning. Reading in $a$ Foreign Language, 20(2), 232-245. https://eric.ed.gov/?id=EJ815123
Webb, S., \& Chang, A. (2014). Second language vocabulary learning through extensive reading with audio support: How do frequency and distribution of occurrence affect learning. Language Teaching Research, vol. 19(6), 667686.

https://doi.org/10.1177\%2F136216881455980 0

Wilhelm, I., Rose, M., Imhof, K. I., Rasch, B., Büchel, C., \& Born, J. (2013). The sleeping child outplays the adult's capacity to convert implicit into explicit knowledge. Nature Neuroscience, 16, 391-393. https://doi.org/10.1038/nn.3343

Wilhelm, I., Diekelmann, S., \& Born, J. (2008). Sleep in children improves memory performance on declarative but not procedural tasks. Learning \& Memory, 15(5), 373-377. https://doi.org/10.1101/lm.803708

Wolter, B., \& Helms-Park, R. (2016). The role of lexical knowledge in second language reading. In X. Chen, V. Dronjic, \& R. Helms-Park (Eds.), Reading in a second language: cognitive and psycholinguistic issues. Routledge.

Yap, M. J., Balota, D. A., Sibley, D. E., \& Ratcliff, R. (2012). Individual differences in visual word recognition: insights from the English Lexicon Project. Journal of Experimental Psychology Human Perception \& Performance, 38(1), 53-79. https://doi.org/10.1037/a002417

\footnotetext{
i Automatic defined as the learner's ability to perform very quickly and with little or no effort (Segalowitz, 2010, p.53)
} 